\title{
UM CONTO EXEMPLAR
}

Ariovaldo Vidal*

Resumo: O artigo empreende uma leitura analítica do conto "Caso de mentira", de Marques Rebelo (1907-73), que faz parte do seu livro de estréia - Oscarina (193I). Narrado pelo irmão mais velho, o conto fala de uma dupla travessura: a do irmão mais novo, que termina bem, e a do mais velho, castigado pelo pai autoritário, o que implica a presença de um tema machadiano no conto - o sentimento de um destino equivocado - ao mesmo tempo configurando uma cena da tradição patriarcal da família brasileira.

Palavras-chave: Marques Rebelo; “Caso de mentira”; estrutura e tema

Por mais de uma razão, "Caso de mentira”, de Marques Rebelo, é um conto exemplar. Desde sua estréia, com o livro Oscarina (1931), Rebelo debateu-se com a forma de sua narrativa, dando a essa questão o estatuto de um tema central de sua obra. Era para ele, sem dúvida, um problema decisivo, que perpassou seus contos e romances, como algo dilacerado. Nesse livro de estréia, que chamou atenção da melhor crítica da época, a questão aparece tratada ora pelo próprio autor, ora pela crítica, sendo o início em sua obra de um diálogo entre o que havia feito e recusava, o que não fizera e buscava, em termos de estrutura e estilo, este caudatário da prosa realista brasileira, de Almeida e Machado, posta agora no registro cotidiano herdado do primeiro modernismo.

* Professor de Teoria Literária e Literatura Comparada da FFLCH-USP. 
Mas era sobretudo na construção do enredo, no desdobramento das personagens que sua obra mostrava uma liberdade responsável pelo que o escritor faria de melhor e, ao mesmo tempo, de menos acabado. Ao comentar os contos de Oscarina, Mário de Andrade já sentira o problema desde o conto de abertura, que dá nome ao volume; chamara-o de "obra-prima" - além de elogiar outros contos do conjunto -, mas dissera também: "Conto, ou o que quer que seja. Talvez a única reserva que se possa fazer a esta página é acabar tão cedo. $\mathrm{Na}$ verdade se trata dum romance, e a impressão que a gente tem é que o autor se cansou de repente e acabou porque quis acabar" (1976, p. 376).

E, de fato, os dezesseis contos do livro oscilam desde essa possível novela que dá nome ao volume até peças que são instantâneos da vida interior de personagens anônimas; de registros poéticos de uma tarde de sol à vida caricata de uma pequena classe média, tratada no registro da crônica humorística. E por isso o mencionado "Caso de mentira" é um conto exemplar: fala desse contista às voltas com a construção que oscila entre uma forma tradicional e outra, aberta; ora afeito à poética do conto realista do XIX, ora imerso no quadro do conto moderno, posterior a Tchekhov. ${ }^{1}$ Essa breve narrativa de que tratamos tem um caráter tão acabado, chegando quase à forma de uma poética da short-story; para lê-la, é preciso encará-la com os procedimentos próprios a uma forma simples e, nesse sentido também, perceber sua construção de feição exemplar.

"Caso de mentira" se abre com um parágrafo dividido em duas partes simétricas, sendo a primeira construída com verbos no pretérito imperfeito, criando uma situação de equilíbrio para a cena doméstica descrita: moravam o narrador e sua família "numa boa casa de dois pavimentos",

I Na verdade, o próprio Mário voltou ao assunto mais tarde, por ocasião do aparecimento de $A$ estrela sobe (1939), quando formula uma distinção entre o "romance aberto e o fechado" para dar conta do problema na obra do autor, algo que já vinha de seus contos (I972, p. I26). 
em São Francisco Xavier, ainda que o pai por essa época não estivesse em condições de "arrastar, sem alguma dificuldade, o luxo de residência tão ampla e confortável”. Ainda assim, faz questão de notar o narrador que "temos que perdoar a ele, entre outras fraquezas, esta da ostentação, já que a perfeição foi negada por Deus à alma das criaturas".

Nessas linhas, portanto, e na forma de um sumário narrativo, o narrador registra a condição razoável de sua família, com "poucas amizades", morando em boa casa de subúrbio no Rio, em que, a despeito do registro das imperfeições do pai (com uma ponta de ironia do filho?), a vida caminhava normalmente, sem que nada fosse motivo de drama e, portanto, de narrativa. Mas a segunda parte do parágrafo será justamente a quebra dessa situação de equilíbrio, com a entrada de um acontecimento decisivo para a vida pacata da família; os verbos passam para o pretérito perfeito e a narração se particulariza numa única ação, destacada do fluxo temporal: "Eis, senão quando", o irmão Aluísio, "o demônio em figura de gente", pratica uma travessura que deixa a todos temerosos das conseqüências: deita por terra "o rico vaso, um legítimo Satzuma", que o pai "freqüentemente gabava” pela sua qualidade e, a mãe, por ter pertencido ao avô que era barão e morrera na Europa.

Assim, completa-se a construção inicial da narrativa, com uma abertura semelhante às histórias elementares, pois fica clara a construção dual do primeiro parágrafo: na primeira parte, o sumário resume o ritmo regular da casa paterna, ao passo que, na segunda, se instaura um nó dramático. Dizendo de outro modo, a primeira parte é dominada literalmente pela figura do pai e sua ostentação, enquanto a segunda, pela figura do irmão e sua diabrura.

Ao chegar do serviço, o pai fica sabendo do ocorrido, e faz soar sua voz tenebrosa pela casa, chamando pelo filho "endiabrado", o que causa arrependimento à mãe pela nomeação do autor da diabrura, bem como pavor à empregada; esta, a "preta Paulina" chamada de Lalá, e que "trouxera o nosso herói ao colo desde o seu primeiro dia, chorava e rezava no 
corredor, espiando". O temor de todos era inteiramente justificado pois, como diz o narrador, o pai "sabia ser violentíssimo", quando para isso the davam "fortes motivos".

Ocorre que o garoto, à beira da situação trágica diante do pai enfurecido, sai-se com uma história tão inesperada e viva na narração, cheia de lances rocambolescos e aventuras, que o pai, pego de surpresa pela segurança de Aluísio ao contar as façanhas, acaba caindo numa "tremenda gargalhada", e mandando o filho brincar, satisfeito com a imaginação fértil do garoto que lhe reservaria, com certeza, muito orgulho no futuro. "Você ainda há de dar coisa na vida!", sentencia o pai, repetindo exaustivamente aos parentes e conhecidos dali em diante a proeza de fantasia de Aluísio.

A cena termina, assim, com a absolvição do filho peralta - "muito imaginativo" e de "profunda sagacidade" -, cheia de humor e alívio pelo desenlace do nó, que se desata de forma imprevista. $\mathrm{Na}$ verdade, a surpresa está no fato de o episódio se resolver de forma contrária à expectativa armada pelo narrador. Ou seja, ocorre na cena do pai irado e, posteriormente, rindo de modo desbragado o procedimento da peripécia, como o descreveu Aristóteles e o faria um contista brasileiro de 30: uma reviravolta nos acontecimentos, contrária à expectativa da cena, criando uma espécie de cruzamento surpreendente.

A peripécia, nesse caso, liga-se de modo intrínseco ao relato que lemos, pois ocorre graças a um procedimento narrativo de Aluísio, que consegue convencer o pai, ouvinte de seu relato. Ao recontar a lenda do "caso do bandido" para agradar às visitas, o pai instaura uma narrativa que esconde a verdadeira história do "caso do vaso de faiança", como diz o narrador, compreendendo a extensão do feito do irmão; ou seja, o que seria a falta de Aluísio, aparece como a qualidade do filho, na versão do pai. Mas a menção à situação atual do irmão, que se tornou um advogado "incontestavelmente bem colocado, com uma bonita carreira na sua frente", sugere que a brincadeira infantil transformou-se - na idade adulta e 
no país dos bacharéis - em hipocrisia, embuste. $\mathrm{E}$ ao dizer que o irmão está longe da carreira que o pai profetizara é irônico também, sugerindo que não se tratava propriamente de um talento, e sim de oportunismo. Como recompensa pela história, Aluísio ganha liberdade para brincar durante semanas, dando vazão à sua natureza de garoto folgazão, até que o pai acaba pondo um freio na sua indisciplina, e manda o "vagabundo" tomar jeito.

Concluída a primeira volta dramática da ação, o conto poderia terminar. Entretanto, se o fizesse, mais (ou menos) do que um conto, a narrativa teria uma feição de crônica contando uma estripulia de infância, próxima, por exemplo, às de Fernando Sabino. Entretanto, o narrador agora entra como personagem central de seu relato, e o conto inicia uma segunda parte. Para que a narrativa ganhe a envergadura de um conto, é preciso que a primeira - que já faz parte do conto - ganhe a significação que terá com a presença da segunda; ocorre aqui uma construção paralelística, conforme a descreveu o formalismo russo. ${ }^{2}$

Assim, ocorre novamente um momento de equilíbrio na narrativa, descrito também agora de modo sumariado, iniciando-se uma segunda unidade dramática. E a segunda já se anuncia com maior gravidade, pois o narrador - apenas testemunha da primeira parte - agora entra em cena, o que leva a crer que a aventura do irmão peralta diz respeito, de modo decisivo, à sua condição: "Mas, origens e transformações, tudo são injustiças neste mundo, rótulos de ouro e mercadorias baratas, tanto assim que falhei, redondamente, na primeira ocasião que tentei empregar o mesmo método do mano Aluísio".

A segunda parte do conto dá à primeira uma significação maior, à medida que ela é também muito mais densa que a anterior, com a

2 Chklóvski, I97I, p. 216-220. O paralelismo explícito, em que uma história se explica pelo confronto com a outra, é tido justamente como forma elementar de construção, o que não decide necessariamente sobre a qualidade da obra. 
qual cria o sentido todo da história. A maior densidade está agora não só no fato de ser o narrador seu protagonista, como também no maior desenvolvimento que a segunda unidade dramática - o segundo episódio que se anuncia - terá. E isso porque o segundo episódio aventuresco de criança está marcado por uma complexidade maior de motivações.

Por essa razão, a parte em sumário narrativo, que introduz o episódio, agora é bem maior e mais complexa, articulando-se a mais de um motivo. Tudo nasce do desejo inconfessável do narrador em possuir uma peteca, com a qual sonhava mais do que com qualquer outro brinquedo; sendo assim, a aventura que irá narrar nasce não apenas de uma ação praticada por estripulia: é motivada por um desejo e, por extensão, por uma razão que se liga à interioridade do narrador. Essa implicação funda aparece dada claramente na frase que indicia o seu drama: "pura verdade é o que conto e a mim é quanto me basta".

Como diz, nada o proibia de pedir a peteca aos pais, mas sua timidez não o levava a esse pedido, mostrando a introversão do garoto e a dificuldade em dar uma solução ao seu desejo. É interessante também que, assim como na primeira parte do conto havia uma identidade entre o pai severo e o filho traquinas (Aluísio), na expansão de temperamento de ambos, agora aparece a mãe em cena, nos passeios à cidade acompanhada do filho mais velho, mais “ajuizado", criando entre pais e filhos uma distinção clara de temperamentos. Diga-se que, enquanto Aluísio fazia diabruras para não ter de ir à cidade, o mais velho suportava, em sua timidez, os passeios com "secretos padecimentos", a que ele chamava de "tragédia".

O episódio da brincadeira de peteca que, por infelicidade, resultará na quebra de uma moringa do pai - "da qual somente papai bebia a sua água" -, é precedido pela entrada em cena de uma personagem fora do círculo familiar - Seu Souza, um amigo do pai, proprietário de terrenos em Botafogo, e homem maçante, que a mãe só suportava porque colocava o marido "pouco abaixo das coisas celestes". A presença do amigo do pai é importante na história: em princípio, é uma espécie de portador do 
instrumento que fará a felicidade e infelicidade do garoto; assim, a peteca chega às mãos do narrador trazida pelo acaso, contra o desejo que teimava em se esconder, ocultar. Mas mais do que ser o instrumento do acaso, Seu Souza entra em relação direta com o narrador e seu pai; primeiro porque o narrador também antipatiza com a personagem e, graças a um acaso, muda de atitude bruscamente, mudança que implica um aprendizado existencial para ele, dando uma existência ao tempo, à medida que o preenche de experiência. Como ele mesmo diz, "nessa tarde excepcional" - quando o sujeito aparece com o brinquedo - o narrador consegue compreender "o segredo difícil das simpatias". Assim, a segunda peripécia do conto será mais densa pela dimensão existencial das descobertas do tempo da infância.

Entretanto, a presença do homem é importante também por outro motivo: antecipa, de modo irônico, o desencanto com o pai. O último segmento, correspondendo propriamente ao episódio, repete o primeiro de forma invertida, dando ao conto aquela construção cruzada de que fala E. M. Forster, na forma de ampulheta (I969, p. II8). Também agora se trata de uma peripécia, nos mesmos termos da anterior: o menino, por descuido, deixa a peteca bater na moringa que o pai utiliza quando chega suado e sedento do trabalho, e resolve, para se livrar de um possível castigo, imitar o irmão, contando um caso fantasioso para agradar ao pai. Como era "pouco imaginativo", porém, não conseguira "encaixar nenhuma passagem de extraordinário realce"; e pelo meio da história, o pai já o interrompia com um "tabefe na boca", chamando-o de mentiroso, e dizendo, "com dureza, que um homem que mentia não era um homem".

Essa segunda peripécia é também mais densa que a primeira: o irmão traquinas havia sido perdoado; a moringa de agora era "comuníssima", sem o valor do vaso anterior; e não havia antecedentes contra o filho ajuizado; pela expectativa criada, a solução da peripécia poderia ser intuída pelo leitor, o que daria em certa atenuação de efeito. Ocorre que ela é mais densa que a anterior, pois o que perde em inesperado, ganha em 
dimensão de sentido, dando à narrativa a envergadura do conto, entendido como concentração da vida num ato decisivo.

Assim - e para continuarmos nos termos da poética aristotélica, utilizando-a livremente -, do ponto de vista da construção a densidade maior em relação à primeira peripécia surge do fato de que essa traz consigo um dado fundamental da ação dramática, a que Aristóteles chamou de anagnórise (ou reconhecimento), esse movimento de ânimo, no âmbito da emoção, que marca a passagem do desconhecido ao conhecimento, através de uma discrepância como os laços de família destruídos por sentimentos hostis. Por certo, não se trata aqui da revelação nos termos em que a cultura de massa empregou e emprega o procedimento, em que a revelação traduz sempre, em chave apelativa, o drama do rei infortunado; mas sim da revelação como acontecerá no conto moderno, de um momento privilegiado para a consciência de uma condição existencial. ${ }^{3}$

A noção de anagnórise pode ser estendida à teoria do conto, gênero próximo ao dramático pela compressão temporal e que, como o drama, caminha rápido para o desenlace; para vários de seus comentadores, o conto passa a ser entendido como gênero propício à revelação epifânica, entendendo-se esta como uma "súbita manifestação espiritual", conforme a definiu James Joyce, espécie de aparição que se traduz numa imagem poética; daí encerrar-se no desenlace do nó, logo após seu clímax, concentrando em seu efeito final toda carga dramática. ${ }^{4}$

3 Cortázar dirá que a condição própria do conto - de abrir de par em par uma realidade muito mais ampla que o episódio de partida - fará que sua matéria se converta "no resumo implacável de uma certa condição humana, ou no símbolo candente de uma ordem social ou histórica" (1993, p. I5I-I53).

4 Umberto Eco, ao comentar o Dublinenses, diz que a epifania passa a ser na narrativa seu "clímax, resumo e juízo sintético", aparecendo como "momentos-chave, momentos-símbolo de uma dada situação", "denúncia de certo vazio e inutilidade da existência” (apud Sá, 1979, p. I49). A importância do desfecho como limite do conto está, entre outros, em Boris Eikhenbaum (I971, p. I6I-I68), em que o teórico retoma as idéias de Edgar Allan Poe. 
Assim, a cena infeliz do narrador não é uma simples peripécia; mas uma peripécia que, articulada ao reconhecimento de sua condição, implica um momento de revelação existencial; esta deixa de ser um fato externo, percebido por todos, para ser uma compreensão que se dá por meio de uma reflexão solitária do narrador. A narrativa passa a ser uma experiência de autoconhecimento, atestado até mesmo pelo fato de um narrador já adulto narrar um episódio perdido na infância.

O conto termina com o castigo do filho exemplar, que vê o irmão indiferente a seu sofrimento - "insensível à minha prisão, folgava, não parecendo sentir a falta do companheiro" - e deixando transparecer claramente um sentimento de inveja pelo talento do outro: "Da janela do meu quarto, enquanto descansava as mãos doloridas de copiar, com boa letra e sem nenhum erro, as trinta páginas da minha geografia, que papai, pela manhã, antes de sair, inflexivelmente, me marcava, ficava vendo-o correr, subir às árvores, com desembaraço e agilidade. E invejava-o surdamente. Tinha dez anos."

A revelação que tem o narrador - ou subjaz ao mito narrado por ele - articula-se a alguns temas descritos por Antonio Candido, ao tratar da obra de Machado de Assis, influência decisiva para Marques Rebelo. ${ }^{5}$ A relação conflituosa que se dá entre o narrador e seu irmão prenuncia todo o desdobramento desse tema em seu romance-diário $O$ espelho partido (1959-68), com a rivalidade insuperável entre Eduardo (o narrador) e Emanuel (o irmão diplomata), tema e situação que o autor deve ter encontrado (enquanto leitor) na obra de Machado, bastando lembrar do romance Esaú e Jacó (1904). Nessa relação conflituosa, o contraste ou oposição constante entre um narrador e seu duplo - advogado, diplomata, mentiroso, malandro, sedutor - que parece conhecer as regras do jogo social, ou ter uma habilidade natural para jogá-las; e, por seu lado, o

5 Refiro-me ao conhecido ensaio "Esquema de Machado de Assis", de Vários escritos (1970), em que o autor trata de alguns temas da obra, a partir de seus críticos mais importantes, entre eles Augusto Meyer.. 
narrador - cuja obra confessional mostra estar sempre preocupado com a verdade ("pura verdade é o que conto e a mim é quanto me basta"), sempre dilacerado pela constatação do engano, do equívoco, da vocação que não tem língua, para usar a expressão do narrador de "Cantiga de esponsais", em cuja obra Rebelo foi buscar ou alimentar seus temas. O resultado é uma consciência amarga e reflexiva, às voltas com o "sentido do ato”, para usar a expressão do crítico, e que acaba por se reconhecer, também ele, um gauche na vida.

A compreensão que tem de si e sua condição é a de um destino falhado, sem vocação, que se completa com o desdobramento, nos livros de Rebelo, do desejo angustiado pela busca de uma grande obra, que parece até o fim escapar de seu intento, tema também obsedante e matéria constante de reflexão na série de $O$ espelho partido. Nesse sentido, o conto que lemos faz papel para o narrador de sucedâneo da história traumática da infância e cumpre a condição da narrativa moderna, a de nascer de um fracasso.

Entretanto, para compreender o narrador e sua condição é preciso ver com maior detalhamento não apenas a relação entre os dois irmãos, mas também a relação entre os dois e o pai, pois o conto parece jogar toda ênfase na situação moral da casa paterna. E para isso, é preciso reler algumas implicações desse espaço social e, de modo mais particularizado, as cenas reveladoras.

Quando ocorre a primeira peripécia - que acaba bem, com a gargalhada do pai e a absolvição do filho -, o narrador já havia descrito o quadro social e mental da casa paterna, a vida numa família de classe média marcada decisivamente pela condição patriarcal e escravista da formação brasileira, com a falta de liberdade de todos diante da figura opressora do pai. $\mathrm{O}$ vaso era herança de um avô barão que morrera na Europa, e a empregada - a "preta Paulina, chamada de Lalá" - é tratada na chave do caricato. Ou seja, a origem patriarcal da casa e colonial do país explica as 
relações entre pais e filhos, incluindo aí a condição da mulher diante do marido, bem como a presença do "compadre".

A família do conto está situada num momento de mudança das relações domésticas, guardando ainda hábitos da formação patriarcal antiga, por um lado, e traços modernos, por outro, como por exemplo a desvinculação da autoridade entre os irmãos. $\mathrm{O}$ quadro literário do período mostra vários tipos ou feições de família, em função do desenvolvimento desigual das regiões do país; se pelo lado rural, aparece no romance de 30 a personalidade típica do contexto patriarcal e truculento, como o pai do narrador de Infância (1945), de Graciliano Ramos - o chicote em casa e a palmatória na escola -, aqui surge uma figura de herança patriarcal, mas num quadro já de urbanização, criando o contraste jocoso (tão explorado pelo modernismo) entre o verniz do pai de família entusiasmado com a beleza do Satzuma - "isto é que é a verdadeira arte, meninos!" - e o tosco de sua figura, pronto a descer a mão nos filhos. Essa situação de passagem e desequilíbrios da família fechada em torno do chefe para outra de relações mais abertas está em toda a obra de Rebelo, bastando mencionar a oscilação do papel da mulher, em função das diferentes situações: compare-se nesse sentido a atitude da mãe do conto que estamos lendo - que não gostava de "sair sozinha", levando sempre o filho mais velho quando devia ir à cidade - com a de Leniza, heroína de A estrela sobe, que, num quadro familiar mais frouxo pela situação econômica e um pouco posterior, de certo modo faz da cidade sua casa.

Aristóteles exigia da peripécia, por mais inesperado que fosse o desfecho, ater-se às leis da verossimilhança - ainda que seja sempre preferível o impossível que convença -; ora, nesse caso, o inesperado se ajusta ao arbítrio do pai, que não perdoa o filho por outro motivo que não seja o gozo da anedota. Assim, o que é peripécia no plano estrutural da ação dramática transforma-se no conto em arbitrariedade no plano das relações familiares. Ou seja, a absolvição do filho não se deve tanto às condições e à ação praticada, mas ao acaso de agradar ou não ao pai autoritário. De- 
pendendo da arbitrariedade, das oscilações de humor, a peripécia acaba bem ou mal; não à toa que, depois de dar liberdade ao filho para brincar à vontade, soe estranho o xingamento de "vagabundo" a Aluísio, o mesmo filho que era o orgulho da crônica de família. E a malandragem do garoto completa o quadro, convivendo com a violência e insensibilidade para o sofrimento do outro, como quando corta o rabo da gata malhada de Lalá com o machado, reproduzindo, a seu modo, o autoritarismo paterno. ${ }^{6}$

Quando é a vez do narrador passar pelo confessionário, mente e recebe o castigo mencionado. E nesse caso, a mentira torna-se a negação do valor supremo da classe média: "um homem que mente não é homem”. Na verdade - e só a verdade importa ao narrador - ele não tem a intenção de mentir, nem mesmo de invejar o irmão; sua atitude se justifica unicamente pela atitude do pai, de quem espera receber o mesmo reconhecimento ou evitar as temíveis conseqüências. Ou seja, quer imitar o gesto que, aos olhos do próprio pai, era uma qualidade. Fazendo isso, o ato praticado e a reação paterna ganham a dimensão de uma cena de formação para o narrador e, no mesmo passo, as conseqüências desastrosas para sua sensibilidade. Nesse sentido, o conto reencena a situação do machadiano "Conto de escola", de Várias histórias (I896), em cujo espaço também se dá o aprendizado da "corrupção", pelo mesmo desejo de fugir aos castigos do pai e professor.

Assim, o narrador - ou a visão implicada que vai além dele - expõe às claras que a revelação - a consciência de sua condição - nasce de um ato arbitrário e autoritário do pai, do qual depende a verdade do narrador; ou seja, seu conflito (a falta de vocação, o destino falhado, o "gauche na vida" etc.) depende dessa cena autoritária, que o irmão dribla pela malandragem, e à qual ele paga o alto preço dos honestos e ingênuos. Desconsiderando a cena patriarcal (num suposto universalismo), a leitura anularia

6 Alfredo Bosi vê no conto de Otto Lara Resende e outros contistas contemporâneos a mistura de educação e sadismo na formação tradicional da infância brasileira, contistas para os quais aponta Marques Rebelo como um dos precursores (I975, p. I6-I7). 
o conto, à medida que deixaria de considerar o que o próprio narrador empenhou-se em determinar: o aprendizado da casa paterna, uma casa que mostra as marcas da formação do país, ainda ecoando o consórcio de cristianismo e escravidão.

O conto - em sua relação pai e filho, filho e irmão - antecede o conhecido "A terceira margem do rio", de Primeiras estórias (1962), de Guimarães Rosa, em que também ali a presença paterna se faz de forma autoritária, ainda que invertendo a atitude ao fazer-se antes pela opressão do silêncio - e mostrando a superioridade de seu autor; também ali, "os nexos de amor e culpa" aparecem articulados à arbitrariedade das relações de família (Galvão, 1978, p. 39). Ao final do conto de Rebelo, o narrador confessa sua culpa - "as bagagens da vida", na expressão do outro narrador -, ao dizer que invejava o irmão, tendo ainda dez anos. E o sentimento de culpa, já no título do conto e pairando sobre toda a história, faz lembrar a frase extraordinária do atormentado narrador rosiano: "De que era que eu tinha tanta, tanta culpa?”. Num caso e noutro, guardando-se as devidas dimensões, o conto de Rebelo e o de Rosa se inserem na linhagem do conto moderno e contemporâneo do Brasil, conto que, na expressão de Alfredo Bosi, tem sabido falar de "situações exemplares".

\section{Bibliografia}

Andrade, Mário de. "A Estrela sobe". O empalhador de passarinho. 3. ed. São Paulo: Martins, 1972.

. "Oscarina”. Táxi e crônicas no Diário Nacional. Org. de Telê Porto Ancona Lopes. São Paulo: Duas Cidades, 1976.

Bosı, Alfredo. "Situação e formas do conto brasileiro contemporâneo". $O$ conto brasileiro contemporâneo. São Paulo: Cultrix, 1975.

Candido, Antonio. "Esquema de Machado de Assis". Vários escritos. São Paulo: Duas Cidades, r970. 
Chrlóvski, Viktor. "A construção da novela e do romance". Teoria da literatura: formalistas russos. Trad. de Regina Zilberman et al. Porto Alegre: Globo, 1971.

Cortázar, Julio. "Alguns aspectos do conto". Valise de cronópio. Trad. de Davi Arrigucci Jr. e João Alexandre Barbosa. 2. ed. São Paulo: Perspectiva, 1993.

Einhenbaum, Boris. "Sobre a teoria da prosa". Teoria da literatura: formalistas russos, ed. cit.

Forster, E.M. Aspectos do romance. Trad. de Maria Helena Martins. Porto Alegre: Globo, I969.

Galvão, Walnice Nogueira. "Do lado de cá". Mitológica rosiana. São Paulo: Ática, 1978.

Rebelo, Marques. "Caso de mentira". Contos reunidos. Rio de Janeiro: José Olympio, 1977.

Sá, Olga de. "O termo e o conceito de epifania em Joyce". A escritura de Clarice Lispector. Petrópolis: Vozes, 1979.

Авstract: This article undertakes an analytical reading of the story "Caso de mentira" ("Lie case") by Marques Rebelo (1907-73), which is part of his debut book "Oscarina" (193I). Narrated by the older brother, the story deals with a double mischief: the one of the younger brother that ends well, and the one of the older one, punished by the authoritarian father, which is a typical theme of the novels and short stories written by the Brazilian XIX century writer Machado de Assis: the perception of a mistaken destination which, at the same time, sets the scene of a patriarchal tradition of the Brazilian family.

Keywords: Marques Rebelo; "Caso de mentira" ("Lie Case"); structure; and theme 